\title{
Cavernous Sinus Cavernoma Treated with Radiation Therapy
}

- Case Report-

\author{
Masaharu MARUISHI, Takeshi SHIMA*, Yoshikazu OKADA*, \\ Masahiro NISHIDA*, Kanji YAMANE*, and Shinji OKITA* \\ Department of Neurosurgery, Inokuchi Hospital, Higashihiroshima, Hiroshima; \\ *Department of Neurosurgery, Chugoku Rousai Hospital, Kure, Hiroshima
}

\begin{abstract}
A 71-year-old female presented with a syncopal attack. She underwent surgery for what appeared to be a meningioma. However, a small incision in the dura mater caused severe bleeding. Histological examination of the biopsy specimen showed sinus cavernoma with an incomplete pseudocapsule. The dura mater encapsulated the cavernous sinus cavernoma, explaining the severe bleeding from the dural incision. She was treated with Linac irradiation ( 40 Gy) which resulted in a decrease in tumor size. Radiation therapy is indicated for the treatment of cavernous sinus cavernoma, especially if associated with severe intraoperative bleeding.
\end{abstract}

Key words: cavernous sinus cavernoma, radiation therapy

\section{Introduction}

Extra-axial cavernous angiomas may originate from the cavernous sinus and grow via capillary outgrowth and ectasia of the vascular spaces, suggesting that "sinus cavernoma" is a more appropriate term for this lesion. ${ }^{17)}$ Magnetic resonance (MR) imaging has shown that many cavernous angiomas in the middle cranial fossa actually originate from the cavernous sinus. ${ }^{10,15)}$ The clinical symptoms reflect involvement of the cranial nerves in and around the cavernous sinus, and increase with physical exertion possibly secondary to vascular engorgement in the cavernous sinus cavernoma. ${ }^{3)} \mathrm{Ad}$ vances in skull base surgery have allowed some of these lesions to be completely excised, but the risk of massive intraoperative bleeding remains high. Radiation therapy may be beneficial for treating extra-axial cavernous angiomas in the middle cranial fossa. ${ }^{19,34,35)}$

We present a 71-year-old female with cavernous sinus cavernoma treated by radiation therapy after surgical excision failed.

Received January 5, 1994;

Accepted July 16, 1994

\section{Case Report}

A 71-year-old female suffered a syncopal attack and was admitted to the Chugoku Rousai Hospital. Neurological examination was normal on admission. A plain craniogram disclosed erosion of the left sphenoid bone. Computed tomography (CT) showed a slightly high-density mass lesion measuring $3.5 \times$ $3.5 \times 4.0 \mathrm{~cm}$ in the left middle cranial fossa with marked homogeneous postcontrast enhancement. MR imaging $(2.0 \mathrm{~T})$ revealed a lesion in the left parasellar region that extended into the cavernous sinus. The mass was low intensity on the $\mathrm{T}_{1}$-weighted images, high intensity on the $\mathrm{T}_{2}$-weighted images, and strongly enhanced after gadolinium-diethylenetriaminepenta-acetic acid (Gd-DTPA) administration (Fig. 1). Thickening of the dura mater (the socalled 'meningeal sign') was not detected. A left carotid angiogram showed closing of the carotid siphon in the arterial phase and a persistent finely flecked tumor supplied by the meningohypophyseal and inferior cavernous sinus arteries (Fig. 2). No stenosis of the internal carotid artery was detected. The preoperative diagnosis was meningioma.

A standard left pterional approach was used. After the Sylvian fissure was opened, a dark-red, 

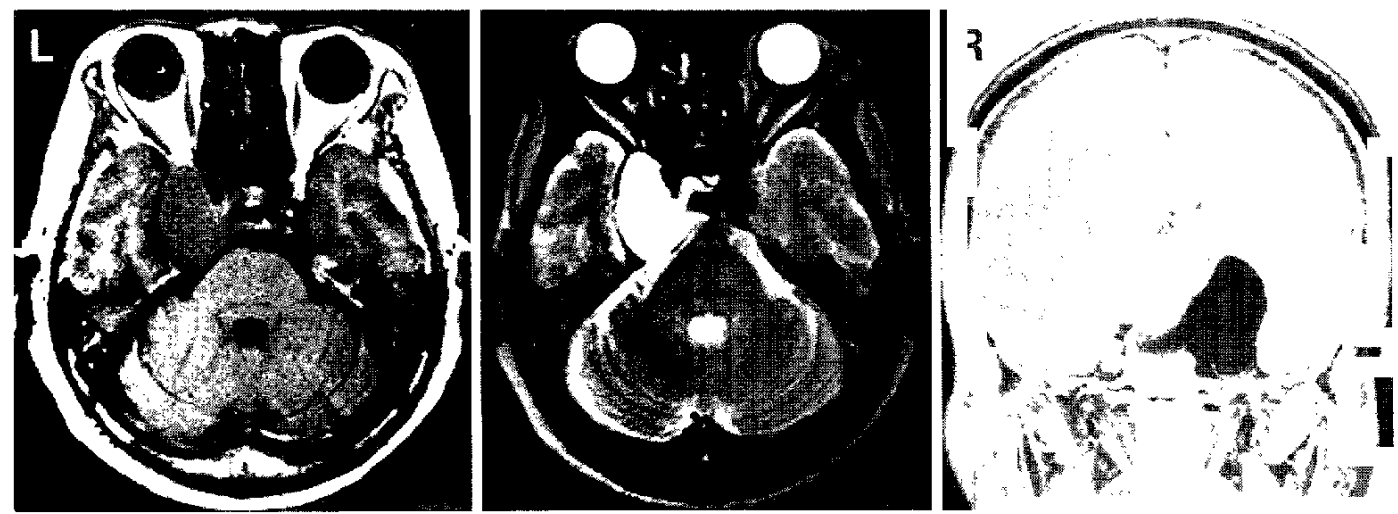

Fig. 1 MR imaging of the brain showing a homogeneous low-intense lesion on the $\mathrm{T}_{1}$-weighted image (left), and a strongly high-intensity lesion on the $\mathrm{T}_{2}$-weighted image (center). The lesion occupies the area of the cavernous sinus. The $T_{1}$-weighted image shows homogeneous enhancement after administration of Gd-DTPA (right).

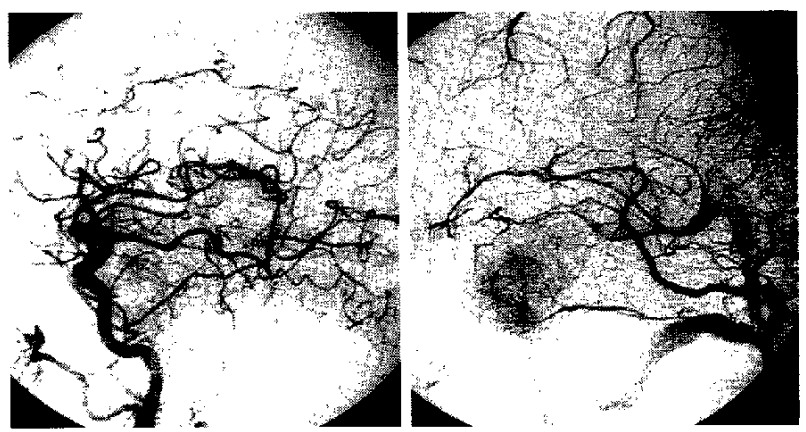

Fig. 2 Left carotid angiograms showing the meningohypophyseal and inferior cavernous sinus arteries supplying the lesion, and staining in the venous phase. The cavernous portion of the internal carotid artery is not stenosed. left: arterial phase, right: venous phase.

elastic, firm tumor was found outside the internal carotid artery covered by the dura mater. A small incision of the dura mater caused severe bleeding which was difficult to control. The intraoperative histological diagnosis was cavernous angioma. The bleeding was stopped with much difficulty and the surgical site was then closed.

Histological examination of the tumor biopsy specimen demonstrated honeycomb-shaped, thinwalled vessels without intervening neural tissue, characteristic of cavernous angioma. The dura mater was intimately attached to the angioma and appeared to form its capsule. Reactive connective tissue such as collagenous membrane or neovascularization (the so-called "pseudocapsule") was not detected (Fig. 3).

She had a mild left oculomotor nerve paresis for

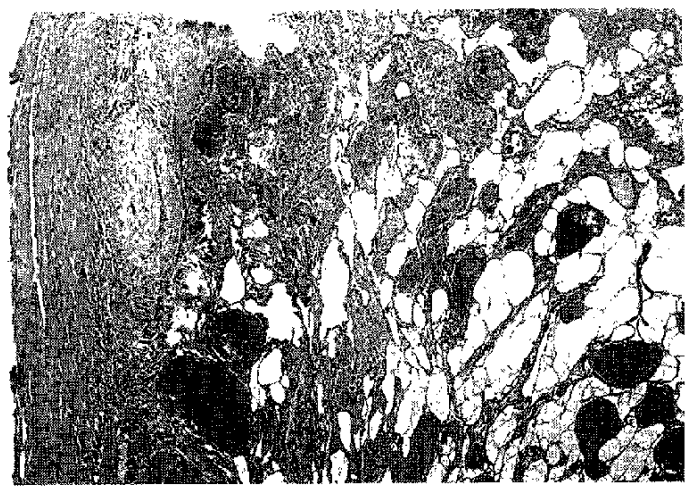

Fig. 3 Photomicrograph showing a cavernous hemangioma consisting of endothelium-lined vascular spaces intimately attached to the dura mater which appears to form the capsule of the cavernous hemangioma. Hematoxylin and eosin stain, $\times 100$.

several weeks postoperatively which finally resolved. She received postoperative local radiation therapy (total 40 Gy) using the Linac method. Eight months after completion, MR imaging demonstrated a moderate decrease in the tumor size to $2.0 \times 2.0 \times$ $2.0 \mathrm{~cm}$ (Fig. 4). No neurological or hormonal disturbance developed after radiation therapy.

\section{Discussion}

Neuroimaging diagnosis of cavernous sinus cavernomas requires that the tumor is continuous with the cavernous sinus. The CT appearance is commonly a well-demarcated, homogeneous, and slightly hyper- 


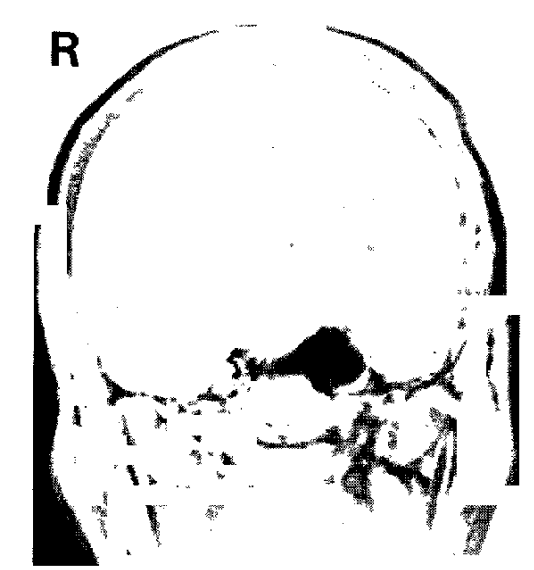

Fig. $4 \mathrm{~T}_{1}$-weighted $\mathrm{MR}$ image 5 months after radiation therapy showing a moderate reduction in the lesion size.

dense lesions. ${ }^{10)}$ MR imaging shows iso- or hypo-intense lesions on the $\mathrm{T}_{1}$-weighted images, and iso- or hyper-intense on the $T_{2}$-weighted images, strongly enhanced after Gd-DTPA administration. ${ }^{10)}$ Carotid angiography frequently demonstrates delayed but persistent, finely flecked tumor staining. These findings are similar to those of meningiomas. ${ }^{30}$

Another important aspect of this tumor is the effect on the neighboring structures. Bone changes were detected in 32 of the 57 previous cases of cavernous sinus cavernoma. ${ }^{1-28,31-39)}$ Twenty-five cases showed erosion or remodeling, and one showed hyperostosis of the posterior orbital wall.5) Angiography was performed in 21 cases, but detected no stenosis of the internal carotid artery. Kudo et al. ${ }^{13)}$ and Sepehrnia et al. ${ }^{31)}$ reported that the internal carotid artery was not stenotic despite the complete involvement of the cavernous sinus. No changes in the dura mater or the so-called meningeal sign were reported. ${ }^{29)}$ Thus, cavernous sinus cavernoma does not present as an invasive tumor, but rather causes a mass effect in the surrounding structures.

These findings suggest that cavernous sinus cavernoma may grow by capillary outgrowth and present clinical symptoms secondary to the mass effect on the surrounding structures. ${ }^{17}$ ) Therapy for cavernous sinus cavernoma should aim at decreasing the mass effect and improve the clinical symptoms.

Attempted removal of extra-axial cavernous angiomas has a reported perioperative mortality of $38 \% .^{5}$ Advances in skull base surgery have gradually improved operative results. The outcomes in 22 of 44 cases of cavernous sinus cavernomas treated by surgical removal alone showed a perioperative mortality of $32 \%$ and a morbidity of $50 \%$, mainly postoperative extra-ocular nerve palsy. In addition, many reports described severe bleeding which was difficult to control.

Linskey and Sekhar ${ }^{15)}$ demonstrated the presence of a pseudocapsule in cavernous sinus cavernoma and claimed that it was easy to dissect the pseudocapsule of the tumor from the surrounding structures without significant blood Ioss. They thought that this pseudocapsule was always present around cavernous sinus cavernoma. Even if the pseudocapsule was always present, dissection between the dura and the pseudocapsule without causing damage to the pseudocapsule would not always be technically easy. In fact, diffuse bleeding occurred in several cases due to rupture of the pseudocapsule during dissection. ${ }^{738)}$ In our patient, the pseudocapsule was incomplete at the biopsy site, and severe bleeding occurred after the dura mater was incised. Meyer et $a l{ }^{17)}$ reported a similar pathological presentation. In our case and three others, ${ }^{9,21,23)}$ excessive bleeding occurred even though only a dural incision was performed. Therefore, a pseudocapsule firmly encapsulating the tumor is not always present, rendering surgical treatment difficult.

Radiation therapy decreases the size of cavernous sinus cavernomas by reducing the blood volume in the tumor. In one case, a tumor removed after radiation therapy revealed marked narrowing of the vessels with edematous changes in the interstitial tissues. ${ }^{32)}$ Twelve published cases of cavernous sinus cavernoma have been treated with radiation therapy (Table 1). Two patients received only radiation, ${ }^{32,39)}$ six received radiation therapy after the failure of surgical removal, ${ }^{4,17,19,25,34)}$ and four had surgical removal of the residual tumor after radiation therapy. ${ }^{19,25,32)}$ Ten of the 12 tumors shrank and one disappeared $^{32)}$ after radiation therapy. The tumor did not decrease in size in one patient treated with proton beam therapy. ${ }^{25}$ Almost every patient experienced an improvement in neurological symptoms after radiation therapy, showing that most symptoms were due to the mass effect. All four unfavorable outcomes, ${ }^{25,34)}$ including one death, ${ }^{34)}$ were due to operative complications, and there were no significant complications caused by radiation therapy. Four tumors were removed after radiation therapy with minimal bleeding ${ }^{19,25,321}$ except for the patient who received the proton beam treatment. ${ }^{25)}$

Cavernous sinus cavernoma responds well to either ${ }^{60} \mathrm{Co}$ or Linac irradiation in total doses ranging from 30 to $50 \mathrm{~Gy}$. Some tumors respond to even lower doses, and at least one tumor has continued to 
Table 1 Cavernous sinus cavernoma treated with radiation therapy

\begin{tabular}{|c|c|c|c|c|c|}
\hline Author (Year) & $\begin{array}{l}\text { Age/ } \\
\text { Sex }\end{array}$ & Symptoms & Radiation & $\begin{array}{l}\text { Size of cavernoma } \\
\text { after treatment }\end{array}$ & Outcome \\
\hline \multicolumn{6}{|l|}{ Radiation only: } \\
\hline Shibata and Mori $(1987)^{32)}$ & $62 / \mathrm{F}$ & vertigo & $50 \mathrm{~Gy}$ & disappeared & good \\
\hline Yamamoto et al. $(1992)^{39)}$ & $34 / \mathrm{F}$ & hyperprolactinemia & 50 Gy (Linac) & significant reduction & good \\
\hline \multicolumn{6}{|c|}{ Radiation after biopsy or partial removal: } \\
\hline Mori et al. $(1980)^{19)}$ & $50 / \mathrm{F}$ & $\begin{array}{l}\text { exophthalmos, } \\
\text { ptosis }\end{array}$ & $30 \mathrm{~Gy}$ & significant reduction & good \\
\hline Harada et al. $(1982)^{4)}$ & $57 / \mathrm{F}$ & quadrantanopia & $50 \mathrm{~Gy}\left({ }^{60} \mathrm{Co}\right)$ & significant reduction & - \\
\hline Meyer et al. $(1990)^{17)}$ & - & - & $40 \mathrm{~Gy}$ & significant reduction & - \\
\hline Rigamonti et al. $(1990)^{25)}$ & $51 / \mathrm{F}$ & headache, diplopia & $50 \mathrm{~Gy}$ & significant reduction & $\begin{array}{l}\text { fair (trochlear } \\
\text { nerve palsy) }\end{array}$ \\
\hline Takano et al. $(1992)^{34)}$ & $72 / \mathrm{F}$ & hemiparesis & $45 \mathrm{~Gy}\left({ }^{60} \mathrm{Co}\right)$ & significant reduction & died \\
\hline Present case & $71 / \mathrm{F}$ & syncope & 40 Gy (Linac) & significant reduction & good \\
\hline \multicolumn{6}{|l|}{ Total removal after radiation: } \\
\hline Mori et al. $(1980)^{19)}$ & $44 / \mathrm{F}$ & visual disturbance & $50 \mathrm{~Gy}$ & significant reduction & good \\
\hline Shibata and Mori $(1987)^{32)}$ & $52 / \mathrm{F}$ & grand mal seizure & $30 \mathrm{~Gy}$ & moderate reduction & good \\
\hline \multirow[t]{2}{*}{ Rigamonti et al. $(1990)^{25)}$} & $42 / \mathrm{F}$ & ptosis, diplopia & $50 \mathrm{~Gy}$ & significant reduction & $\begin{array}{c}\text { fair (extraocular } \\
\text { nerve palsy) }\end{array}$ \\
\hline & $37 / \mathrm{F}$ & diplopia & proton beam & no change & $\begin{array}{l}\text { fair (ophthalmo- } \\
\text { plegia) }\end{array}$ \\
\hline
\end{tabular}

—: unknown.

shrink after the completion of radiation therapy ${ }^{3+1}$ and disappeared 19 months later. ${ }^{32)}$ The best strategy for radiation therapy may be to use a low dose ( 30 Gy) of ${ }^{60} \mathrm{Co}$ or Linac irradiation, and to follow up the patient for at least 1 year.

Cavernous sinus cavernomas grow without invading the surrounding structures, and their natural history is poorly understood. Therefore, there is no evidence to support total excision. We believe that radiation therapy is the optimum treatment for cavernous sinus cavernoma because of its safety and efficacy. However, cavernous sinus cavernoma is often difficult to diagnose, so biopsy may be necessary to confirm the diagnosis. If a diagnosis of cavernous sinus cavernoma is made intraoperatively and the lesion cannot be removed without significant bleeding, radiation therapy should be used.

\section{References}

1) Ahmadi J, Miller CA, Serall HD, Park SH, Zee CS, Becker RL: CT patterns in histologically complex cavernous hemangiomas. AJNR 6: 389-393, 1985

2) Bradac GB, Riva A, Schorner W, Stura G: Cavernous sinus meningiomas: An MRI study. Neuroradiology 29: 578-581, 1987

3) Dolenc VV: Comment on Sepehrnia A, Tatagiba M, Brandis A, Samii M, Prawitz RH: Cavernous angioma of the cavernous sinus: Case report. Neurosurgery 27: 155, 1990
4) Harada $T$, Aoyama N, Terada $H$, Tsujimoto $S$, Hosogi Y, Iwasaki S: A case of extracerebral hemangioma of the middle fossa. CT Kenkyu 4: 460465, 1982 (in Japanese)

5) Harper DG, Buck DR, Early DO: Visual loss from cavernous hemangiomas of the middle cranial fossa. Arch Neurol 39: 252-254, 1982

6) Ichikizaki K, Shiobara R, Shizana H, Iizaka Y, Toya S, Ohuchi T, Suzuki S, Shiga $\mathbf{H}$, Ohtani M, Mikawa $\mathrm{K}$, Izumi G: The usefulness of computed tomography for the diagnosis of intracranial cavernous hemangiomas. CT Kenkyu 2: 319-327, 1980 (in Japanese)

7) Ishijima $Y$, Matsumura $H$, Kageyama $N$ : Intracranial cavernous hemangioma: Report of two cases. Nippon Geka Hokan 35: 748-754, 1966 (in Japanese)

8) Ishikawa $\mathbf{M}$, Handa $\mathbf{H}$, Moritake $K$, Mori K, Nakano Y, Aii $\mathrm{H}$ : Computed tomography of cerebral hemangiomas. I Comput Assist Tomogr 4: 587-591, 1980

9) Ito J, Takahashi M, Saito A, Honda H, Yajima K, Ueki K: A case of cavernous hemangioma of the middle fossa with visualization of the feeding artery and faint tumor stain in cerebral angiography. Rinsho Hoshasen 22: 339-344, 1977 (in Japanese)

10) Katayama $Y$, Tsubokawa $T$, Miyazaki S, Yoshida K, Himi K: Magnetic resonance imaging of cavernous sinus cavernous hemangiomas. Neuroradiology 33: 118-122, 1991

11) Kawaguchi $S$, Ohsawa $T$ : A case of cavernous hemangioma at the base of skull. Rinsho Shinkeigaku 5: 705-708, 1965 (in Japanese) 
12) Kawai K, Fukui M, Tanaka A, Kuramoto S, Kitamura K: Extracerebral cavernous hemangioma of the middle fossa. Surg Neurol 8: 19-25, 1978

13) Kudo T, Ueki S, Kobayashi H, Torigoe H, Tadokoro M: Experience with the ultrasonic surgical aspirator in a cavernous hemangioma of the cavernous sinus. Neurosurgery 24: 628-631, 1989

14) Laws ER Jr: Comment on Sepehrnia A, Tatagiba M, Brandis A, Samii M, Prawitz RH: Cavernous angioma of the cavernous sinus: Case report. Neurosurgery 27: 155,1990

15) Linskey ME, Sekhar LN: Cavernous sinus hemangiomas: A series, a review, and an hypothesis. Neurosurgery 30: 101-107, 1992

16) Matias-Guiu X, Alejo M, Sole $T$, Ferrer I, Noboa R, Bartumeus F: Cavernous angiomas of the cranial nerves: Report of two cases. J Neurosurg 73: 620622, 1990

17) Meyer FB, Lombardi D, Scheithauer B, Nichols DA: Extra-axial cavernous hemangiomas involving the dural sinuses. I Neurosurg 73: 187-192, 1990

18) Moore T, Ganti SR, Mawad ME, Hiral SK: CT and angiography of primary extradural juxtasellar tumors. AJR 145: 491-496, 1985

19) Mori K, Handa H, Gi H, Mori K: Cavernoma in the middle fossa. Surg Neurol 14: 21-31, 1980

20) Nakasu $Y$, Handa J, Matsuda $M$, Koyama T: Cavernous angioma of the middle fossa: Report of two cases and a review. Nippon Geka Hokan 54: 364-371, 1985 (in Japanese)

21) Namba S: Extracerebral cavernous hemangioma of the middle cranial fossa. Surg Neurol 19: 379-388, 1983

22) Numaguchi $Y$, Kishikawa T, Fukui M, Sawada K, Kitamura K, Matsuura K, Rossou WJ: Prolonged injection angiography for diagnosing intra-cranial cavernous hemangiomas. Radiology 131: 137-138, 1979

23) Odake $G$, Tanaka K: Cavernous hemangioma of the middle fossa: Case report and review of the literature. Neurol Med Chir (Tokyo) 26: 58-67, 1986

24) Ogasawara S, Nakazawa K, Katsura S, Oizumi S: Cavernoma on the intracranial base: Report of a case. No To Shinkei 25: 735-737, 1973 (in Japanese)

25) Rigamonti D, Pappas CTE, Spetzler R, Johnson PC: Extracerebral cavernous angiomas of the middle fossa. Neurosurgery 27: 306-310, 1990

26) Rosenblum B, Rothman AS, Lanzieri C, Song S: A cavernous sinus cavernous hemangioma. Case report. J Neurosurg 65: 716-718, 1986

27) Savoiardo M, Passerini A: CT, angiography, and RN scans in intracranial cavernous hemangiomas. Neuroradiology 16: 256-260, 1978

28) Sawamura Y, Tribolet N: Cavernous hemangioma in the cavernous sinus. Neurosurgery 26: 126-128, 1990

29) Schorner W, Schubeus $P$, Henkes $H$, Lanksch W, Felix R: "Meningeal sign": A characteristic finding of meningiomas on contrast-enhanced MR images. Neuroradiology 32: 90-93, 1990

30) Sekhar LN, Altschler EM: Meningioma of the cavernous sinus, in Al-Mefty $\mathrm{O}(\mathrm{ed})$ : Meningiomas. New York, Raven Press, 1990, pp 445-460

31) Sepehrnia A, Tatagiba M, Brandis A, Samii M, Prawitz RH: Cavernous angioma of the cavernous sinus. Neurosurgery 27: 151-155, 1990

32) Shibata S, Mori K: Effect of radiation therapy on extracerebral cavernous hemangioma in the middle fossa. Report of three cases. $J$ Neurosurg 67: 919922, 1987

33) Shibata S, Mori K: Delayed effect of radiation therapy on extracerebral cavernous angioma in the middle fossa. No Shinkei Geka 16: 1005-1008, 1988 (in Japanese)

34) Takano K, Daita G, Yonemasu $Y$, Makino K, Takahashi T, Ogawa K: A case of extracerebral cavernous hemangioma in the middle fossa. No To Shinkei 44: 271-275, 1992 (in Japanese)

35) Tsuiki K, Abe S, Chiba M, Murakami H, Saiki I, Kanaya H: A case of cavernous angioma of the middle cranial fossa originating in the cavernous sinus with hyperprolactinemia. No Shinkei Geka 15: 301305, 1987 (in Japanese)

36) Voci A, Panzarasa G, Formaggio G, Arrigoni M, Geuna E: Les cavernomes de localisation rare. 4 observations personnelles. Neurochirurgie 35: 99-101, 1989

37) Waga S: Cavernous angiomas. No Shinkei Geka 9: 881-895, 1981 (in Japanese)

38) Watanabe M: Ein Fall von Parasellarcavernom. Nippon Geka Hokan 20: 473-477, 1943 (in Japanese)

39) Yamamoto $Y$, Weining $Z$, Ohashi $T$ : Intracavernous cavernous hemangioma: Dynamic CT findings and effectiveness of irradiation. Case report. Neurol Med Chir (Tokyo) 32: 93-95, 1992

Address reprint requests to: M. Maruishi, M.D., Department of Neurosurgery, Inokuchi Hospital, 951-1 Doyomaru, Saijo-cho, Higashihiroshima, Hiroshima 724 , Japan. 